\title{
Relationship of ewe reproduction with subjectively assessed wool and conformation traits in the Elsenburg Merino flock
}

\author{
P. A. M. Matebesi-Ranthimo ${ }^{1,2 \#}$, S. W. P. Cloete ${ }^{3,4}$, J. B. van Wyk $^{2}$ \& J. J. Olivier ${ }^{4}$ \\ ${ }^{1}$ National University of Lesotho, P.O. Roma 180, Roma Lesotho \\ ${ }^{2}$ University of the Free State, P.O. Box 339, Bloemfontein 9300, South Africa \\ ${ }^{3}$ University of Stellenbosch, Private Bag X1, Matieland, 7602, South Africa \\ ${ }^{4}$ Institute for Animal Production: Elsenburg, Private Bag X1, Elsenburg, 7609, South Africa
}

(Received 4 August 2016; Accepted 11 October 2017; First published online 6 November 2017)

\author{
Copyright resides with the authors in terms of the Creative Commons Attribution 4.0 South African Licence. \\ See: http://creativecommons.org/licenses/by/4.0/za \\ Condition of use: Theuser may copy, distribute, transmit and adapt the work, but must recognise the authors and the South African \\ Journal of Animal Science.
}

\begin{abstract}
Subjectively assessed wool and conformation traits are widely used to select breeding ewes and rams in the sheep industry. Data from a Merino flock that is maintained at Elsenburg Research Farm were used to investigate animal model (co)variance components for ewe reproduction traits with subjectively assessed wool and conformation traits. Ewe reproduction traits were assessed at their first lambing opportunity at two years, or over a three-year period from their lambing opportunities at two to four years old. Relationships of ewe reproduction traits with subjectively measured wool and conformation traits were also investigated. All these traits were heritable, with a range from $0.16 \pm 0.03$ for topline (TOPL) to $0.64 \pm 0.04$ for woolly face score (WFS). Genetic correlations of number of lambs born (NLB1) with colour (COL), number of lambs weaned (NLW1) with COL and belly and points (BANDP) and total weight of lamb weaned (TWW1) with COL were negative and significant. Significant genetic correlations of ewe reproduction traits over three lambing opportunities were found between number of lambs born (NLB3) and WFS $(0.23 \pm 0.11)$ and between total weight weaned (TWW3) and face cover score (FCS) $(-0.33 \pm 0.16)$. Among these traits, the noteworthy favourable genetic correlation between total fold score (TOT) and NLB1 suggested that plainer ewes were more reproductive. This is important for the South African Merino industry as plainer sheep are more desirable because of their faster growth and higher lambing percentages and reduced chances of fly strike. Selection for improved ewe reproduction in Merino sheep thus would not result in marked unfavourable correlated responses in most of these subjective wool and conformation traits.
\end{abstract}

Keywords: Correlations, heritability

\#Corresponding author: pmatebesi@gmail.com

\section{Introduction}

Subjectively assessed wool and conformation traits are widely used to select ewes and rams in Merino (Snyman \& Olivier, 2002; Naidoo et al., 2004; Matebesi et al., 2009a) and Dorper sheep (Olivier \& Cloete, 2006; Zishiri et al., 2013) of South Africa. Therefore, subjective traits need to be considered in sheep breeding research to provide the genetic parameters that are essential for the development of breeding plans. Research in South Africa (Snyman \& Olivier, 2002; Naidoo et al., 2004; Olivier \& Cloete, 2006; Matebesi et al., 2009a Matebesi et al., 2009b; Zishiri et al., 2013; Olivier, 2014) and other countries (Lewer et al., 1995; Mortimer et al., 2009; Mortimer et al., 2010) reported genetic variation for these traits. In particular, subjective body conformation and wool quality are associated with better production and enhanced wool value, thus contributing to the viability and economic progress of sheep farming (Mortimer et al., 2010; Olivier, 2014). Positive correlated responses to selection for economically important wool quality and conformation traits have been reported in Australian Merino flocks (Mortimer et al., 2010).

Studies that involve the relationships of subjective wool and conformation traits with ewe reproduction, however, are confined to studies by Snyman \& Olivier (2002), Olivier et al. (2006), and Olivier (2014). Research on these relationships is essential to assess putative correlated responses in ewe reproduction when selection is based on subjectively assessed wool and confirmation traits. A companion paper 
(Matebesi-Ranthimo et al., 2017) assessed the relationships of ewe reproduction with objectively measured traits using the same Merino resource flock. Therefore, the aim of this study is to investigate the relationships of ewe reproduction with subjectively assessed wool and conformation traits in South African Merino sheep.

\section{Materials and Methods}

Data from a Merino flock maintained at the Elsenburg Research Farm were used to investigate animal model (co)variance components for ewe reproduction with subjectively assessed wool and conformation traits. Ewe reproduction traits were measured at their first lambing opportunity at two years or over a threeyear period from their lambing opportunities at two to four years old. Details of selection practices applied in the flock and the husbandry and management practices applied to the experimental animals and heritability for ewe reproduction traits are fully described by Matebesi-Ranthimo et al. (2017) and will not be repeated here. These traits included number of lambs born at the first lambing opportunity at approximately two years old (NLB1), number of lambs weaned at the first lambing opportunity (NLW1), total weight of lamb weaned at the first lambing opportunity (TWW1), number of lambs born from two to four years old (NLB3), number of lambs weaned from two to four years old (NLW3) and total weight of lamb weaned from two to four years old (TWW3). These traits, NLB1, NLW1, TWW1, NLB3, NLW3 and TWW3 were expressed per lambing opportunity (Matebesi-Ranthimo et al., 2017). Subjective traits were assessed according to a linear scale ranging from 1 to 50 (Table 1; Olivier et al., 1987) at 11 to 12 months old as described by Matebesi et al. (2009a). Wool traits included in the current study were face cover score (FCS), pigmentation (PIGM), woolly face score (WFS), quality (QUAL), regularity of crimp (ROC), colour (COL), wool yolk (OIL), staple formation (STAPL) and belly and points (BANDP). Conformation traits included general head conformation (GEN), hocks (HOCKS), front quarters (FQ), pastern score (PS), top line (TOPL) and total fold score (TOT). The statistics of data used in this investigation are described in Table 2. The data consisted of the records of 4 905 ewes, the progeny of 241 sires and 1502 dams born between 1986 and 2012.

Table 1 Linear scale for assessment of subjectively assessed fleece and conformation traits in Elsenburg Merino sheep (Olivier et al., 1987)

\begin{tabular}{cccc}
\hline \multirow{2}{*}{ Trait } & \multicolumn{3}{c}{ Scale of assessment } \\
\cline { 2 - 4 } & 1 & 25 & 50 \\
\hline
\end{tabular}

\section{Subjective wool traits}

Face cover score (FCS)

Pigmentation (PIGM)

Woolly face score (WFS)

Quality (QUAL)

Regularity of crimp (ROC)

Colour (COL)

Oil (OIL)

Staple formation (STAPL)

Belly and points (BANDP)

Subjective conformation traits

Head general (GEN)

Hocks (HOCKS)

Front quarters (FQ)

Pastern score (PS)

Top line (TOPL)

Total fold score (TOT)

$\begin{array}{ccc}\begin{array}{c}\text { Hard } \\ \text { Excessive }\end{array} & \text { Average } & \text { Soft } \\ \text { Woolly faced } & \text { Average } & \text { None } \\ \text { Poor } & \text { Ideal } & \text { Open faced } \\ \text { Poor } & \text { Average } & \text { Ideal } \\ \text { Yellow } & \text { Average } & \text { Ideal } \\ \text { None } & \text { Average } & \text { White } \\ \text { Ropy } & \text { Ideal } & \text { Excessive } \\ \text { Watery, yellow } & \text { Average } & \text { Thick, blocky } \\ & \text { Average } & \text { Thick, white } \\ \text { Weak } & \text { Average } & \text { Strong } \\ \text { Narrow } & \text { Average } & \text { Wide } \\ \text { Narrow } & \text { Average } & \text { Wide } \\ \text { Weak } & \text { Average } & \text { Strong } \\ \text { Poor } & \text { Average } & \text { Ideal } \\ \text { Plain (score: } 3 \text { ) } & - & \text { Most wrinkly } \\ & & \text { (score: 17) }\end{array}$

This partitioning applied to most of traits: $1-10=$ poor; $11-20=$ below average; $21-30=$ average; $31-40=$ above average; and $41-50=$ excellent. The exceptions were woolly face score and oil, which had an intermediate optimum of 25 
The data editing for ewe reproduction traits was described by Matebesi-Ranthimo et al. (2017), while that of subjectively assessed wool and conformation traits used in this investigation was performed as described in Matebesi-Ranthimo et al. (2014). The ASReml program (Gilmour et al., 2009) was used to perform analyses similar to those applied by Matebesi-Ranthimo et al. (2017). Therefore, fixed effects to be included in the operational model for each trait were tested and the variance components and ratios were estimated as described in Matebesi-Ranthimo et al. (2017). The correlations (genetic, phenotypic and environmental) of ewe reproduction with subjectively assessed wool and conformation traits were obtained by fitting a series of bivariate animal models. These analyses included all the fixed and random effects significant in the single-trait analyses.

Table 2 Descriptive statistics of data used after editing from Elsenburg Merino flock

\begin{tabular}{|c|c|c|c|c|c|}
\hline Trait & $\mathbf{n}$ & Mean & SD & CV\% & Range \\
\hline \multicolumn{6}{|l|}{ Subjective wool traits } \\
\hline Face cover score & 3600 & 25.94 & 4.51 & 17.39 & $1-50$ \\
\hline Pigmentation & 3640 & 39.19 & 8.43 & 21.51 & $5-50$ \\
\hline Woolly face score & 3215 & 29.63 & 7.65 & 25.82 & $1-50$ \\
\hline Quality & 3640 & 31.90 & 7.83 & 24.55 & $5-50$ \\
\hline Regularity of crimps & 3640 & 33.77 & 7.26 & 21.50 & $5-50$ \\
\hline Colour & 3640 & 34.75 & 6.38 & 18.36 & $4-50$ \\
\hline Oil & 3640 & 26.27 & 5.24 & 19.95 & $2-49$ \\
\hline Staple formation & 3640 & 26.30 & 4.25 & 16.16 & $5-46$ \\
\hline Belly and points & 3417 & 26.01 & 4.48 & 17.22 & $10-48$ \\
\hline \multicolumn{6}{|l|}{ Subjective conformation traits } \\
\hline Total fold score & 4661 & 8.15 & 2.75 & 33.74 & $3-17$ \\
\hline General head conformation & 3696 & 25.00 & 5.15 & 20.60 & $1-45$ \\
\hline Hocks & 3518 & 24.82 & 5.28 & 21.27 & $1-48$ \\
\hline Front quarters & 3599 & 23.60 & 4.03 & 17.08 & $1-45$ \\
\hline Pastern score & 3599 & 32.44 & 7.29 & 22.47 & $1-48$ \\
\hline Topline & 3955 & 26.59 & 4.57 & 17.19 & $1-47$ \\
\hline
\end{tabular}

n: number of records; SD: standard deviation; CV\%: coefficient of variation; first parity: NLB1: number of lambs born; NLW1: number of lambs weaned; TWW1: total weight weaned per ewe; Three lambing opportunities: NLB3: number of lambs born; NLW3: number of lambs weaned; TWW3: total weight weaned per ewe

\section{Results and Discussion}

Models were selected according to the log likelihood ratio test as described by Matebesi-Ranthimo et al. (2017). Log likelihood values obtained from single-trait analyses of subjectively assessed wool and conformation traits are presented in Table 3 . Model 1, with only the direct additive effect as a random effect fitted the data best for FCS, PIGM, WFS, QUAL, ROC, STAPL, BANDP, HOCKS, FQ, PS and TOPL. Model 3 , which included direct and maternal genetic effects as random effects, fitted the data best for COL, while Model 4, with direct and maternal genetic effects and their covariance, fitted the data best for OIL. The WFS was the only trait affected by the direct genetic and dam permanent environmental effects (Model 2).

All these wool traits (Table 4) were heritable, with a range of estimates from 0.19 for regularity of crimp $(R O C)$ to 0.64 for WFS. OIL was the only trait that was affected by the maternal additive effect and the covariance between the direct and maternal animal effects. The maternal influence contributed $9 \%$ to the total phenotypic variance with the direct maternal correlation amounting to -0.33 . The maternal genetic effect was also present in wool colour, amounting to $4 \%$ of the total phenotypic variance. A dam permanent 
environmental effect of $3 \%$ affected WFS. The present heritability estimates are generally higher than those reported by Matebesi-Ranthimo et al. (2014) for Tygerhoek Merino resource flock, with the exception of estimates for $\mathrm{COL}$, which were higher at Tygerhoek. The present results accorded well with those reported for Cradock fine wool Merinos for the corresponding traits (Olivier, 2014).

Table 3 Log likelihood ratios for random effects models fitted to subjectively assessed wool and conformation traits data obtained from Elsenburg Merino resource flock with 'best' models in bold

\begin{tabular}{lllllll}
\hline & Model 1 & Model 2 & Model 3 & Model 4 & Model 5 & Model 6 \\
\hline Subjective wool traits & & & & & & \\
Face cover score & -6647.80 & -6647.65 & -6647.65 & $\mathrm{~N} / \mathrm{C}$ & -6647.65 & $\mathrm{~N} / \mathrm{C}$ \\
Pigmentation & $\mathbf{- 4 1 9 6 . 1 4}$ & -4196.14 & -4196.16 & $\mathrm{~N} / \mathrm{C}$ & -4196.14 & $\mathrm{~N} / \mathrm{C}$ \\
Woolly face score & -7733.57 & $-\mathbf{7 7 3 1 . 0 4}$ & -7733.05 & $\mathrm{~N} / \mathrm{C}$ & -7733.04 & $\mathrm{~N} / \mathrm{C}$ \\
Quality & $\mathbf{- 8 4 9 4 . 8 6}$ & -8494.86 & 8494.38 & -8493.98 & -8494.38 & -8493.38 \\
Regularity of crimps & $-\mathbf{8 5 4 3 . 8 8}$ & -8543.88 & 8543.83 & -8542.26 & -8543.83 & -8542.26 \\
Colour & -6783.84 & -6783.29 & -6778.04 & -6777.04 & -6778.27 & -6777.04 \\
Oil & -6786.89 & -6778.72 & -6777.31 & -6775.61 & -6775.82 & -6773.70 \\
Staple formation & -6763.41 & -6762.81 & -6763.36 & -6762.30 & -6762.81 & $\mathrm{~N} / \mathrm{C}$ \\
Belly and points & -6326.52 & -6326.52 & -6326.52 & -6326.28 & -6326.30 & -6326.28 \\
Subjective conformation traits & & & & & & \\
Total fold score & -5796.62 & -5796.29 & -5795.74 & -5794.84 & -5795.74 & -5794.84 \\
General head conformation & -5285.39 & -5282.71 & -5280.14 & -5279.40 & -5280.12 & 5279.38 \\
Hocks & $\mathbf{- 7 2 8 0 . 1 9}$ & -7280.19 & -7280.19 & $\mathrm{~N} / \mathrm{C}$ & -7280.19 & $\mathrm{~N} / \mathrm{C}$ \\
Front quarters & -6145.71 & -6145.55 & -6145.61 & -6145.61 & -6145.55 & -6145.55 \\
Pastern score & $\mathbf{- 7 0 2 5 . 9 6}$ & -7025.96 & -7025.95 & -7025.73 & -7025.95 & -7025.73 \\
Topline & $\mathbf{- 6 9 7 6 . 6 5}$ & -6976.65 & -6976.63 & -6975.39 & -6976.63 & -6975.39
\end{tabular}

Model 1: only direct additive as a random effect; Model 2: direct additive and dam permanent environment as random effects; Model 3: direct and maternal additive as random effects; Model 4: direct and maternal additive and their covariance as random effects; Model 5: direct additive; maternal additive and dam permanent environment as random effects; Model 6: direct additive, maternal additive, dam permanent environment and covariance between animal effects as random effects

These conformation traits (Table 5) studied were also heritable, estimates ranging from 0.12 for front quarters (FQ) to 0.54 for TOT. A maternal genetic effect amounting to $7 \%$ of the overall phenotypic variance, was observed for general head conformation score (GEN). The current results are generally in line with those reported by Matebesi et al. (2009a). The results reported recently on Tygerhoek Merino resource flock (Matebesi-Ranthimo et al., 2014) yielded a lower heritability estimate of 0.36 compared with 0.54 for TOT in the present study. Results obtained in another South African Merino resource flock reported by Olivier (2014) yielded higher $h^{2}$ a values for HOCKS (0.61 vs. 0.30$), F Q(0.45$ vs. 0.12$)$ and GEN 0.39 vs 0.25 . Heritability estimates for other traits accorded well with those in the literature.

Estimates of the genetic $\left(r_{g}\right)$, phenotypic $\left(r_{p}\right)$ and environmental $\left(r_{e}\right)$ correlations from the two-trait analyses of ewe reproduction with subjectively assessed wool and conformation traits are presented in Tables 5 and 6, respectively. Most of these correlations were associated with relatively high standard errors compared with the estimate, and thus are not significant. The genetic relationships between ewe reproduction traits at first parity (Table 5) were negative and significant for NLB1 with COL, for NLW1 with COL and BANDP and for TWW1 with COL. Olivier (2014) reported negative relationships for BANDP with NLB and NLW, which accords well with those obtained in this study. The negative correlations between NLB1 and COL suggested that sheep with yellow wool, which is unfavourable in wool processing industries (Venter, 1981), are likely to have a higher birth rate. In addition, sheep that have yellow wool and yellow watery wool in the belly and points areas are more likely to wean multiple lambs. In addition, sheep that have yellow wool are likely to wean more lambs. 
Table 4 (Co)variance components and ratios ( \pm SE) for subjectively assessed wool and conformation traits in the Elsenburg Merino resource flock

\begin{tabular}{|c|c|c|c|c|c|c|c|c|c|c|c|c|c|c|c|}
\hline & FCS & PIGM & WFS & QUAL & ROC & COL & OIL & STAPL & BANDP & TOT & GEN & HOCKS & $\mathbf{F Q}$ & PS & TOPL \\
\hline \multicolumn{16}{|c|}{ (Co)variance components } \\
\hline$\sigma_{a}^{2}$ & 4.01 & 26.36 & 39.81 & 17.18 & 7.84 & 3.49 & 5.15 & 7.75 & 5.91 & 2.90 & 5.14 & 7.83 & 1.34 & 3.19 & 3.05 \\
\hline$\sigma_{m}^{2}$ & - & - & - & - & - & 0.67 & 1.45 & - & - & - & 1.52 & - & - & - & - \\
\hline$\sigma_{p e}^{2}$ & - & - & 1.80 & - & - & - & - & - & - & & & & & & \\
\hline$\sigma_{\mathrm{am}}$ & - & - & - & - & - & - & -0.91 & - & - & & & & & & \\
\hline$\sigma_{e}^{2}$ & 12.16 & 20.89 & 20.66 & 29.02 & 34.39 & 12.04 & 11.37 & 10.15 & 11.01 & 2.43 & 14.31 & 18.25 & 10.28 & 15.63 & 15.93 \\
\hline$\sigma_{p}^{2}$ & 16.17 & 47.25 & 62.27 & 46.20 & 42.23 & 16.20 & 17.06 & 17.90 & 16.92 & 5.33 & 20.97 & 26.08 & 11.62 & 18.82 & 18.97 \\
\hline \multicolumn{16}{|c|}{ Variance ratios (SE) } \\
\hline $\mathrm{h}_{\mathrm{a}}^{2}$ & 0.25 & 0.56 & 0.64 & 0.37 & 0.19 & 0.22 & 0.30 & 0.43 & 0.35 & 0.54 & 0.25 & 0.30 & 0.12 & 0.17 & 0.16 \\
\hline SE & 0.04 & 0.05 & 0.04 & 0.04 & 0.03 & 0.04 & 0.06 & 0.04 & 0.04 & 0.03 & 0.05 & 0.03 & 0.03 & 0.03 & 0.03 \\
\hline $\mathrm{h}_{\mathrm{m}}^{2}$ & - & - & - & - & - & 0.04 & 0.09 & - & - & - & 0.07 & - & - & - & - \\
\hline SE & - & - & - & - & - & 0.01 & 0.03 & - & - & - & 0.02 & - & - & - & - \\
\hline $\mathrm{r}_{\mathrm{am}}$ & - & - & - & - & - & - & -0.33 & - & - & - & - & - & - & - & - \\
\hline SE & - & - & - & - & - & - & 0.15 & - & - & - & - & - & - & - & - \\
\hline$c_{p e}^{2}$ & - & - & 0.03 & - & - & - & - & - & - & - & - & - & - & - & - \\
\hline SE & - & - & 0.01 & - & - & - & - & - & - & - & - & - & - & - & - \\
\hline
\end{tabular}

FCS: face cover score; PIGM: pigmentation; WFS: woolly face score; QUAL: quality; ROC: regularity of crimp; COL: colour; OIL: oil; STAPL: staple formation; BANDP: belly and pints; TOT: total fold score; GEN: general head conformation; HOCKS: hocks; FQ: front quarters; PS: pastern score; TOPL: topline; $\sigma^{2}$ a: direct additive genetic variance; $\sigma^{2}$ : maternal additive genetic variance; $\sigma^{2}$ : permanent environmental variance; $\sigma^{2}$ : residual variance; $\sigma_{p}^{2}$ : total phenotypic variance; $\sigma_{a m}$ : covariance between direct and maternal additive genetic effects; $\mathrm{h}^{2}$ : direct heritability; $\mathrm{h}_{\mathrm{m}}^{2}$ : maternal heritability; $\mathrm{c}^{2}$ pe: permanent environmental effect; $r_{a m}$ : genetic correlation between direct and maternal additive genetic effects and SE: standard error

The genetic relationships between ewe reproduction traits over three lambing opportunities varied in sign (Table 6) and were significant between NLB3 and WFS $(0.23 \pm 0.11)$ and between TWW3 and FCS $(-0.33 \pm 0.16)$. The positive genetic relationship between NLB3 and WFS obtained in this study suggested that sheep with open faces are likely to have multiple births. 
Previous work on Australian Merino sheep (Young et al., 1963) reported both negative and positive relationships between NLB and WFS (in their study these authors term the trait 'face cover score', but their definition corresponds to WFS in the present study) measured at different ages. The comparable genetic correlation between NLB and WFS reported by Young et al. (1963) was negative at -0.12 . However, Young et al. (1963) concluded that there is no indication of genetic and phenotypic antagonism between face cover and fertility in their study, possibly because of the absence of animals with heavily covered faces. Phenotypic and environmental correlations of ewe reproduction traits with subjective wool traits varied in sign and were mostly low in magnitude and negligible.

Table 5 Genetic, phenotypic and environmental correlations $( \pm S E)$ between ewe reproduction traits at first parity and subjectively assessed wool traits in Elsenburg Merino flock

\begin{tabular}{lccc}
\hline Trait & Genetic $\left(r_{\mathrm{g}}\right)$ & Environment $\left(r_{\mathrm{e}}\right)$ & Phenotypic $\left(r_{\mathrm{p}}\right)$ \\
\hline & & & \\
Number of lambs born per ewe & at first parity $X$ & & \\
FCS & $-0.26 \pm 0.18$ & $0.03 \pm 0.04$ & $-0.02 \pm 0.03$ \\
PIGM & $0.02 \pm 0.17$ & $0.06 \pm 0.07$ & $0.04 \pm 0.04$ \\
WFS & $-0.11 \pm 0.14$ & $0.01 \pm 0.05$ & $-0.03 \pm 0.03$ \\
QUAL & $0.01 \pm 0.15$ & $0.07 \pm 0.04$ & $0.05 \pm 0.03$ \\
ROC & $-0.03 \pm 0.18$ & $0.01 \pm 0.04$ & $-0.01 \pm 0.03$ \\
COL & $-0.46^{*} \pm 0.16$ & $0.06 \pm 0.04$ & $-0.03 \pm 0.03$ \\
OIL & $0.09 \pm 0.16$ & $-0.05 \pm 0.04$ & $-0.02 \pm 0.03$ \\
STAPL & $-0.01 \pm 0.15$ & $-0.02 \pm 0.05$ & $-0.02 \pm 0.03$ \\
BANDP & $-0.25 \pm 0.16$ & $0.01 \pm 0.05$ & $-0.05 \pm 0.03$ \\
Number of lambs weaned per & we at first parity $X$ & & \\
FCS & $-0.18 \pm 0.25$ & $-0.04 \pm 0.04$ & $-0.05 \pm 0.04$ \\
PIGM & $0.12 \pm 0.23$ & $0.05 \pm 0.07$ & $0.05 \pm 0.04$ \\
WFS & $-0.15 \pm 0.19$ & $0.04 \pm 0.06$ & $-0.01 \pm 0.04$ \\
QUAL & $0.27 \pm 0.22$ & $0.06 \pm 0.04$ & $0.09 \pm 0.03$ \\
ROC & $0.02 \pm 0.26$ & $0.03 \pm 0.04$ & $0.02 \pm 0.03$ \\
COL & $-0.51^{\star} \pm 0.22$ & $0.03 \pm 0.04$ & $-0.04 \pm 0.03$ \\
OIL & $0.24 \pm 0.23$ & $-0.04 \pm 0.04$ & $-0.01 \pm 0.03$ \\
STAPL & $-0.41 \pm 0.23$ & $0.05 \pm 0.05$ & $-0.02 \pm 0.03$ \\
BANDP & $-0.50^{*} \pm 0.24$ & $0.03 \pm 0.04$ & $-0.04 \pm 0.03$ \\
Total weight of lamb weaned per ewe at first parity X & & \\
FCS & $-0.30 \pm 0.20$ & $-0.06 \pm 0.05$ & $-0.09 \pm 0.03$ \\
PIGM & $0.03 \pm 0.19$ & $0.12 \pm 0.07$ & $0.08 \pm 0.04$ \\
WFS & $0.04 \pm 0.19$ & $0.06 \pm 0.06$ & $0.04 \pm 0.04$ \\
QUAL & $0.23 \pm 0.17$ & $0.07 \pm 0.04$ & $0.09 \pm 0.03$ \\
ROC & $-0.07 \pm 0.21$ & $0.02 \pm 0.04$ & $0.01 \pm 0.03$ \\
COL & $-0.39^{*} \pm 0.19$ & $0.02 \pm 0.04$ & $-0.05 \pm 0.03$ \\
OIL & $0.27 \pm 0.18$ & $-0.07 \pm 0.04$ & $-0.01 \pm 0.03$ \\
STAPL & $-0.24 \pm 0.19$ & $0.01 \pm 0.05$ & $-0.04 \pm 0.03$ \\
BANDP & $-0.28 \pm 0.19$ & $-0.01 \pm 0.05$ & $-0.05 \pm 0.03$
\end{tabular}

FCS: face cover score; PIGM: pigmentation; WFS: woolly face score; QUAL: quality; ROC: regularity of crimp; COL: colour; OIL: oil; STAPL: staple formation; BANDP: belly and pints; *: significant correlation and SE: standard error 
Table 6 Genetic, phenotypic and environmental correlations ( \pm SE) between ewe reproduction traits over three lambing opportunity and subjective wool traits in Elsenburg Merino flock

\begin{tabular}{|c|c|c|c|}
\hline Trait & Genetic $\left(r_{g}\right)$ & Environment $\left(r_{\mathrm{e}}\right)$ & Phenotypic( $r_{p}$ \\
\hline \multicolumn{4}{|c|}{ Number of lambs born over three lambing opportunities $X$} \\
\hline FCS & $-0.12 \pm 0.14$ & $0.01 \pm 0.05$ & $-0.03 \pm 0.04$ \\
\hline PIGM & $0.13 \pm 0.13$ & $-0.02 \pm 0.08$ & $0.04 \pm 0.05$ \\
\hline WFS & $0.23^{*} \pm 0.11$ & $-0.13 \pm 0.07$ & $0.03 \pm 0.04$ \\
\hline QUAL & $0.06 \pm 0.12$ & $0.01 \pm 0.05$ & $0.02 \pm 0.04$ \\
\hline ROC & $0.02 \pm 0.15$ & $-0.02 \pm 0.05$ & $-0.01 \pm 0.03$ \\
\hline $\mathrm{COL}$ & $-0.02 \pm 0.14$ & $0.02 \pm 0.05$ & $0.01 \pm 0.03$ \\
\hline OIL & $-0.02 \pm 0.13$ & $-0.04 \pm 0.05$ & $-0.03 \pm 0.03$ \\
\hline STAPL & $0.03 \pm 0.12$ & $-0.02 \pm 0.06$ & $-0.01 \pm 0.04$ \\
\hline BANDP & $-0.18 \pm 0.13$ & $0.04 \pm 0.06$ & $-0.03 \pm 0.04$ \\
\hline \multicolumn{4}{|c|}{ Number of lambs weaned over three lambing opportunities $X$} \\
\hline FCS & $-0.23 \pm 0.19$ & $-0.04 \pm 0.05$ & $-0.07 \pm 0.04$ \\
\hline PIGM & $0.10 \pm 0.17$ & $0.12 \pm 0.08$ & $0.10 \pm 0.04$ \\
\hline WFS & $0.20 \pm 0.16$ & $-0.07 \pm 0.07$ & $0.01 \pm 0.04$ \\
\hline QUAL & $0.10 \pm 0.16$ & $0.01 \pm 0.05$ & $0.03 \pm 0.04$ \\
\hline ROC & $-0.15 \pm 0.20$ & $0.05 \pm 0.05$ & $0.02 \pm 0.03$ \\
\hline $\mathrm{COL}$ & $-0.04 \pm 0.18$ & $-0.02 \pm 0.05$ & $-0.02 \pm 0.04$ \\
\hline OIL & $-0.07 \pm 0.18$ & $-0.02 \pm 0.05$ & $-0.03 \pm 0.04$ \\
\hline STAPL & $0.01 \pm 0.17$ & $0.05 \pm 0.06$ & $0.04 \pm 0.04$ \\
\hline BANDP & $-0.20 \pm 0.17$ & $0.10 \pm 0.05$ & $0.04 \pm 0.04$ \\
\hline \multicolumn{4}{|c|}{ Total weight of lamb weaned per ewe over three lambing opportunities $X$} \\
\hline FCS & $-0.33^{*} \pm 0.16$ & $-0.06 \pm 0.05$ & $-0.11 \pm 0.04$ \\
\hline PIGM & $0.05 \pm 0.15$ & $0.19 \pm 0.08$ & $0.13 \pm 0.05$ \\
\hline WFS & $0.22 \pm 0.13$ & $-0.05 \pm 0.07$ & $0.05 \pm 0.05$ \\
\hline QUAL & $0.13 \pm 0.15$ & $0.01 \pm 0.05$ & $0.04 \pm 0.04$ \\
\hline ROC & $-0.10 \pm 0.15$ & $0.05 \pm 0.02$ & $0.02 \pm 0.04$ \\
\hline COL & $-0.06 \pm 0.13$ & $-0.01 \pm 0.04$ & $-0.02 \pm 0.03$ \\
\hline OIL & $0.03 \pm 0.16$ & $-0.07 \pm 0.05$ & $-0.04 \pm 0.04$ \\
\hline STAPL & $0.09 \pm 0.14$ & $0.02 \pm 0.06$ & $0.04 \pm 0.04$ \\
\hline BANDP & $-0.10 \pm 0.15$ & $0.09 \pm 0.06$ & $0.05 \pm 0.04$ \\
\hline
\end{tabular}

FCS: face cover score; PIGM: pigmentation; WFS: woolly face score; QUAL: quality; ROC: regularity of crimp; COL: colour; OIL: oil; STAPL: staple formation; BANDP: belly and points; *significant correlation; SE: standard error

The genetic relationships of ewe reproduction traits at first parity (Table 7) and over three lambing opportunities (Table 8) with subjectively assessed conformation traits were positive, with the exception of TOT. Previous work in Australian Merino sheep (Young et al., 1963) reported negative genetic relations for wrinkle score (corresponding trait to TOT in this study) with NLB $(-0.93,-0.31,-0.21)$ and NLW $(-0.78,-0.32$, -0.34) measured at different ages of ewes. Recently, Olivier (2014) reported a negative genetic relationship between wrinkle score and ewe reproduction $(-0.62 \pm 0.29$ between TOT and NLB; $-0.49 \pm 0.24$ between TOT and NLW; and $-0.37 \pm 0.17$ between TOT and TWW). Negative genetic correlations between NLB1 and TOT (Table 7) suggested that plainer ewes are more likely to have multiples. This is important for the South African Merino industry as plainer sheep are more desirable because of their faster growth and higher lambing percentages (Olivier \& Cloete, 1998) and reduced chances of contracting fly strike (Baillie, 1979; Scholtz et al., 2010). Genetic trends in the resource flock used in the present study also suggested that the 
progeny of the line selected for an improved reproduction became heavier and plainer over time (Cloete et al., 2005). Progeny of the line selected for poor reproduction in contrast became lighter and more developed (wrinkly). Research in Australian Merinos accordingly reported that plainer sheep had higher conception rates, more twins and lower mortality levels of ewes and lambs at birth, and their better performance in Australia tended to be highlighted during drought conditions (Atkins, 1980). The results from this study also suggested that ewes with higher scores for GEN and TOPL were more likely to have multiple lambs in their lifetime. Ewes that weaned more lambs were likely to have better scores for FQ and TOPL as suggested by positive genetic correlations of NLW1 with FQ and TOPL. The genetic correlations of TWW1 with GEN, FQ and TOPL were all high and positive indicating that ewes that weaned higher weights of lamb are likely to have better scores for GEN, FQ and TOPL.

Table 7 Genetic, phenotypic and environmental correlations ( \pm SE) for ewe reproduction at first parity and over three lambing opportunities with subjective conformation traits in Elsenburg Merino flock

\begin{tabular}{lccc}
\hline Trait & Genetic $\left(\mathbf{r}_{\mathrm{g}}\right)$ & Environment $\left(\mathbf{r}_{\mathrm{e}}\right)$ & Phenotypic $\left(\mathbf{r}_{\mathrm{p}}\right)$ \\
\hline & & & \\
Number of lambs born per ewe at first parity $X$ & & \\
TOT & $-0.30^{*} \pm 0.14$ & $-0.03 \pm 0.04$ & $-0.08^{*} \pm 0.03$ \\
GEN & $0.51^{*} \pm 0.15$ & $0.08 \pm 0.05$ & $0.18^{*} \pm 0.04$ \\
HOCKS & $0.31 \pm 0.16$ & $0.03 \pm 0.05$ & $0.08^{*} \pm 0.03$ \\
FQ & $0.29 \pm 0.20$ & $0.06 \pm 0.04$ & $0.09^{*} \pm 0.03$ \\
PS & $0.24 \pm 0.20$ & $-0.02 \pm 0.04$ & $0.02 \pm 0.03$ \\
TOPL & $0.46^{*} \pm 0.18$ & $0.02 \pm 0.04$ & $0.09^{*} \pm 0.03$ \\
Number of lambs weaned per ewe at first parity $X$ & & \\
TOT & $-0.19 \pm 0.18$ & $-0.01 \pm 0.04$ & $-0.03 \pm 0.03$ \\
GEN & $0.42 \pm 0.25$ & $0.17 \pm 0.05$ & $0.19^{*} \pm 0.04$ \\
HOCKS & $0.46 \pm 0.29$ & $0.01 \pm 0.04$ & $0.06 \pm 0.03$ \\
FQ & $0.59^{*} \pm 0.27$ & $-0.02 \pm 0.04$ & $0.04 \pm 0.03$ \\
PS & $0.50 \pm 0.27$ & $0.01 \pm 0.04$ & $0.06^{*} \pm 0.03$ \\
TOPL & $0.61^{*} \pm 0.28$ & $0.01 \pm 0.04$ & $0.07^{*} \pm 0.03$ \\
Total weight of lamb weaned per ewe at first parity $X$ & & \\
TOT & $-0.16 \pm 0.14$ & $-0.03 \pm 0.04$ & $-0.05 \pm 0.03$ \\
GEN & $0.70^{*} \pm 0.17$ & $0.15 \pm 0.05$ & $0.24^{*} \pm 0.04$ \\
HOCKS & $0.30 \pm 0.20$ & $0.02 \pm 0.05$ & $0.06^{*} \pm 0.03$ \\
FQ & $0.54^{*} \pm 0.21$ & $-0.01 \pm 0.04$ & $0.06 \pm 0.03$ \\
PS & $0.41 \pm 0.22$ & $-0.01 \pm 0.04$ & $0.05 \pm 0.03$ \\
TOPL & $0.50^{*} \pm 0.22$ & $0.01 \pm 0.04$ & $0.07^{*} \pm 0.03$ \\
& &
\end{tabular}

TOT: total fold score; GEN: general head conformation; HOCKS: hocks; FQ: front quarters; PS: pastern score; TOPL: topline; * : significant correlation; SE: standard error

It is evident that higher reproducing ewes are likely to have better scores for GEN and FQ. Snyman \& Olivier (2002) reported comparable positive correlations for NLB with corresponding traits in Afrino sheep (HEAD vs GEN and front quarters (FQRT) vs FQ). The positive correlations of NLW3 with GEN, HOCKS and FQ suggested better conformation scores in ewes that weaned more lambs. Previous work on Afrino sheep yielded positive genetic correlations for NLW with HEAD and FQRT, which are consistent with the results obtained in this investigation (Snyman \& Olivier, 2002). At Elsenburg, ewes with higher litter weight at weaning had better scores for GEN, HOCKS and FQ, as suggested by high and positive correlations of TWW3 with GEN, HOCKS and FQ. Snyman \& Olivier (2002) reported a similar positive, but high correlation for TWW with GEN and FQRT with the corresponding traits currently studied. Contrary to this study, Olivier \& Cloete (2006) reported a negative and moderate correlation for general conformation using data from the Dorper sheep breed of South Africa. The significant phenotypic relations were low to moderate, ranging from 
0.11 to 0.25 between ewe reproduction and subjectively assessed conformation traits with the exception of those between TOT with NLB3 $(-0.10)$, NLW3 $(-0.06)$ and TWW3 $(-0.09)$. These results generally agree with those reported in South African Merinos (Olivier et al., 2006; Olivier, 2014) and other breeds for corresponding traits (Snyman \& Olivier, 2002; Olivier \& Cloete, 2006).

Table 8 Genetic, phenotypic and environmental correlations $( \pm S E)$ for ewe reproduction over three lambing opportunities with subjective conformation traits in Elsenburg Merino flock

\begin{tabular}{lccc}
\hline Trait & Genetic $\left(r_{\mathrm{g}}\right)$ & Environment $\left(r_{\mathrm{e}}\right)$ & Phenotypic $\left(r_{\mathrm{p}}\right)$ \\
\hline \multicolumn{3}{c}{ Number of lambs born per ewe over three lambing opportunities $X$} \\
TOT & $-0.15 \pm 0.11$ & $-0.08 \pm 0.05$ & \\
GEN & $0.63^{*} \pm 0.12$ & $0.01 \pm 0.07$ & $-0.10^{*} \pm 0.03$ \\
HOCKS & $0.24 \pm 0.13$ & $-0.04 \pm 0.06$ & $0.20^{*} \pm 0.04$ \\
FQ & $0.51^{*} \pm 0.17$ & $-0.04 \pm 0.05$ & $0.04 \pm 0.04$ \\
PS & $0.26 \pm 0.16$ & $-0.04 \pm 0.05$ & $0.06 \pm 0.04$ \\
TOPL & $0.25 \pm 0.16$ & $0.05 \pm 0.05$ & $0.02 \pm 0.04$ \\
Number of lambs weaned per ewe over three lambing opportunities $X$ & $0.09^{*} \pm 0.04$ \\
TOT & $-0.12 \pm 0.15$ & $-0.05 \pm 0.05$ & \\
GEN & $0.64^{*} \pm 0.17$ & $0.08 \pm 0.06$ & $-0.06 \pm 0.03$ \\
HOCKS & $0.49^{*} \pm 0.20$ & $-0.06 \pm 0.05$ & $0.20^{*} \pm 0.04$ \\
FQ & $0.62^{*} \pm 0.22$ & $-0.04 \pm 0.05$ & $0.04 \pm 0.04$ \\
PS & $0.30 \pm 0.20$ & $0.01 \pm 0.05$ & $0.04 \pm 0.04$ \\
TOPL & $0.41 \pm 0.21$ & $0.06 \pm 0.05$ & $0.05 \pm 0.04$ \\
Total weight of lamb weaned per ewe over three lambing opportunities $X$ & $0.11^{*} \pm 0.04$ \\
TOT & $-0.09 \pm 0.12$ & $-0.10 \pm 0.05$ & \\
GEN & $0.83^{*} \pm 0.11$ & $0.01 \pm 0.06$ & $-0.09^{*} \pm 0.03$ \\
HOCKS & $0.41^{*} \pm 0.16$ & $-0.05 \pm 0.06$ & $0.25^{*} \pm 0.04$ \\
FQ & $0.64^{*} \pm 0.18$ & $-0.02 \pm 0.05$ & $0.05 \pm 0.04$ \\
PS & $0.25 \pm 0.18$ & $0.02 \pm 0.05$ & $0.08 \pm 0.04$ \\
TOPL & $0.34 \pm 0.18$ & $0.07 \pm 0.05$ & $0.06 \pm 0.04$ \\
& & $0.11^{*} \pm 0.04$
\end{tabular}

TOT: total fold score; GEN: general head conformation; HOCKS: hocks; FQ: front quarters; PS: pastern score; TOPL: topline; *significant correlation; SE: standard error.

\section{Conclusion}

Most of the genetic correlations of reproduction with subjectively assessed wool traits were unfavourable or not significant. The negative genetic correlations between NLB1 and COL suggested that sheep with yellow wool are likely to have more multiple births. Furthermore, sheep that have yellow wool with yellow watery wool on their belly and points are likely to wean multiple lambs. The genetic correlations of ewe reproduction traits with subjective conformation traits were mostly favourable. Therefore, care must be taken when selecting against yellow watery wool as this can lead to culling potentially high reproducers.

\section{Acknowledgements}

The usual dedicated assistance of Elsenburg technical staff, stimulating discussions with Elsenburg animal sciences staff, and the dedicated input of Elsenburg farm workers are highly appreciated. The National University of Lesotho, THRIP funding of the NRF, NRF, South African wool industry, Western Cape Agricultural Research Trust, Robert S. McNamara Fellowship Programme and Organisation for Women in Science for the Developing World (OWSDW) are gratefully acknowledged for co-funding the study.

\section{Authors' Contributions}

The study was conceived by SWPC, based on the PhD thesis of PAMMR, under the supervision of JBVW, SWCP and JJO. Data were collected by SWPC, and analysis of data and interpretation of results was led by PAMMR with 
assistance of SWPC and JBVW. The manuscript was drafted by PAMMR and critical revision and final approval of the version to be published were done by SWPC, JBVW and JJO.

\section{Conflict of Interest Declaration}

The authors declare that they have no conflicts of interest with regard to this work.

\section{References}

Atkins, K.D., 1980. Selection for skin folds and fertility. Proc. Aust. Soc. Anim. Prod. 13, 174-176.

Baillie, B., 1979. Skin fold can affect lambing percentage. Agricultural Gazette of New South Wales 90, $4-6$.

Cloete, S.W.P., Olivier, J.J., Van Wyk, J.B., Schoeman, S.J. \& Erasmus, G.J., 2005. Genetic parameters and trends for hogget traits in Merino lines divergently selected for multiple rearing ability. Proc. Assoc. Advmt. Anim. Breed. Gen. 16, 24-27.

Gilmour, A.R., Gogel, B.J., Cullis, B.R., Welham, S.J. \& Thompson, R., 2009. ASREML6 User Guide Release 3.0. VSN International Ltd, Hemel Hempstead, HPI IES, UK.

Lewer, R.P., Woolaston, R.R. \& Howe, R.R., 1995. Studies of Western Australian Merino sheep. III Genetic and phenotypic parameter estimates for subjectively assessed and objectively measured traits in ewe hoggets. Aust. J. Agric. Res. 46, 379-388.

Matebesi, P.A., Van Wyk, J.B. \& Cloete, S.W.P., 2009a. Genetic parameters for subjectively assessed wool and conformation traits in the Tygerhoek Merino flock. S. Afr. J. Anim. Sci. 39, 176-187.

Matebesi, P.A., Van Wyk, J.B. \& Cloete, S.W.P., 2009b. Relationships of subjectively assessed wool and conformation traits with objectively measured wool and live weight traits in the Tygerhoek Merino flock. S. Afr. J. Anim. Sci. 39, 188-196.

Matebesi-Ranthimo, P.A.M., Cloete, S.W.P., Van Wyk, J.B. \& Olivier, J.J., 2014. The relationships between faecal worm egg count with subjectively assessed wool and conformation traits in the Tygerhoek Merino flock. S. Afr. J. Anim Sci. 44, 221-227.

Matebesi-Ranthimo, P.A.M., Cloete, S.W.P., Van Wyk, J.B. \& Olivier, J.J., 2017. Genetic parameters for ewe reproduction with objectively measured wool traits in the Elsenburg Merino flock. S. Afr. J. Anim. Sci. 47, 712-722.

Mortimer, S.I., Robinson, D.L., Atkins, K.D., Brien, F.D., Swan, A.A., Taylor, P.J. \& Fogarty N.M., 2009. Genetic parameters for visually assessed traits and their relationships to wool production and live weight in Australian Merino sheep. Anim. Prod. Sci. 49, 32-42.

Mortimer, S.I., Robinson, D.L., Atkins, K.D., Semple, S.J. \& Fogarty N.M., 2010. Predicted responses in Merino sheep from selection combining visually assessed and measured traits. Anim. Prod. Sci. 50, 976-982.

Naidoo, P., Cloete, S.W.P. \& Olivier, J.J., 2004. Heritability estimates and correlations between subjectively assessed and objectively measured fleece traits in Merino sheep. S. Afr. J. Anim. Sci. 34, 38-40.

Olivier, J.J. \& Cloete, S.W.P., 1998. Adaptations in the South African Merino industry to successfully compete with mutton breeds. 5th World Merino Conference, Christchurch, New Zealand. pp. $74-80$.

Olivier, J.J \& Cloete, S.W.P., 2006. Genetic analysis of South African Dorper sheep. Proc. World. Congr. Gen. Appl. Livest. Prod. Bello Horizonte, 13-18 August, 2006.

Olivier, J.J., Delport, G.J., Erasmus, G.J. \& Eksteen, T.J., 1987. Linear type scoring in Merino sheep. Karoo Agric. 3, $1-4$.

Olivier, W.J., 2014. The evaluation of a South African fine wool genetic resource flock. Ph.D. (Agric.) thesis, University of Stellenbosch, Stellenbosch, South Africa.

Olivier, W.J., Olivier, J.J. \& Greyling, A.C., 2006. Correlations of subjectively assessed traits of fine wool Merino sheep with production and reproduction traits. Proc. 41st S. Afr. Soc. Anim. Sci. 3-6 April 2006, Bloemfontein, South Africa.

Scholtz, A.J., Cloete, S.W.P., Van Wyk, J.B., Kruger, A.C.M. \& Van der Linde, T.C.de K., 2010. Influence of divergent selection for reproduction on the occurrence of breech strike in mature Merino ewes. Anim. Prod. Sci. 50, 203209.

Snyman, M.A. \& Olivier, W.J., 2002. Correlations of subjectively assessed fleece and conformation traits with production and reproduction in Afrino sheep. S. Afr. J. Anim. Sci. 32, 88-96.

Venter, J.J., 1981. Yolk in wool. Karoo Agric. 2 (2), 35-38.

Young, S.S., Turner, H.N. \& Dolling, C.H.S., 1963. Selection for fertility in Australian Merino sheep. Aust. J. Agric. Res. $14,460-482$.

Zishiri, O.T., Cloete, S.W.P., Olivier, J.J \& Dzama, K., 2013. Genetic parameter estimates for subjectively assessed and objectively measured traits in South African Dorper sheep. Small Rumin. Res. 109, 84-93. 